\title{
VACCINE HESITANCY: A THREAT TO VACCINE PREVENTABLE DISEASE PROGRAMS
}

\author{
Fazal Ather ${ }^{\natural}$, Akhtar Sherin ${ }^{2}$
}

THIS ARTICLE MAY BE CITED AS: Ather F, Sherin A. Vaccine hesitancy: A threat to vaccine preventable disease programs. Khyber Med Univ J 2019;I I(2):65-6. DOI: 10.35845/kmuj.2019.19538.

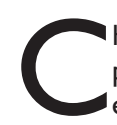

hildhood vaccination program provides one of the most costeffective public health interventions. Vaccination prevents about 2-3 million deaths a year.' Disease elimination and eradication programs are one of the most effective way to interrupt disease transmission, which results in reducing morbidity and mortality. After successful eradication of small pox in $1977,{ }^{2}$ the world is close to achieve the goal of polio eradication. Polio eradication program has evolved since its beginning around three decades ago. However, the program has seen several challenges during this time around the globe. Hesitation to vaccinate remains one of the most important factors to determine the course of eradication program. Vaccine hesitancy is "the reluctance or refusal to vaccinate despite the availability of vaccines".' Any factor affecting the public trust in vaccine safety, purity or efficacy can result in variable level of vaccine hesitancy. $^{3-5}$ Vaccine hesitancy, if not addressed timely and effectively, can hamper the progress of the program and pose challenges to completion of the disease eradication and elimination programs. Vaccine hesitancy affects the coverage and has impact on overall immunity levels and it needs to be taken seriously. Among all public health interventions, immunization programs were able to investigate the details of the reasons for not vaccinating children. Probably, to our knowledge, the polio program has underwent the most indepth exploration on the causes of reluctance to vaccinate than any other public health program. However, vaccine hesitancy is comparatively difficult to capture in routine immunization program. Vaccine hesitancy becomes more obvious during supplementary immunization campaigns as the interventions are for brief time and the time taken by community to react to intervention is short as well. While the goal of eradicating polio is near, the issues of vaccine hesitancy are still adversely affecting the global eradication of polio.

Vaccine hesitancy is a complex issue when it comes to exploring on why the community opts not to vaccinate. The reasons of not-to-vaccinate are not limited to community perception and behavior towards vaccines only. A wide range of reasons for not vaccinating can vary from difficulty to access vaccines, to trusting and believing on vaccination. Attributing factors can be limiting to only one vaccine or generally to overall vaccination program. This needs further exploration in specific contexts. There is always a discrepancy between community perception on benefits of intervention versus reluctance to opt for intervention based on beliefs. With the changing modes of communication from traditional ways like announcements through mosques and mega phone to faster modes through social media, immunization programs face newer challenges to respond to community perceptions. These challenges are more explicitly redefined in case of eradication programs specifically polio eradication.

International technical advisory groups have directed their recommendations to combat the threats posed to vaccine preventable diseases programs. More pronounced is Strategic Advisory Group of Experts (SAGE) recommendations for improved understanding of the issues; improve program capacities to respond to vaccine hesitancy and learning from lessons of other countries. ${ }^{7}$

Polio eradication program had gone through several challenging situations in relation to community perception, during last decade. These became more pronounced in endemic countries where other factors also contributed to existing perceptions of the community to polio vaccines. Field observations indicate that apart from factors like competing priorities in public health, there are other
I Epidemiologist \& Member Editorial Board, Khyber Medical University Journal (KMUJ) Peshawar, Pakistan Email『: fazalather@yahoo.com

2 Chief Editor KMUJ, Khyber Medical University- Institute of Medical Sciences Kohat, Pakistan

factors which attribute to vaccine hesitancy like campaign fatigue, rumors etc. ${ }^{8}$ In recent days, the community trust on vaccines was influenced by antiprogram propaganda in Pakistan.' This resulted in increased hesitancy to vaccinate children during polio national immunization days against this deadly disease, which paralyses children for life and it left the program to ponder on the reasons which led to this situation at a time when the global eradication of polio seems very near. It seems that the intensity and spread of rumors would not have been this much, had it not been through social media. It was also an indication that rumors can confuse the parents and sabotage the gains made by program over decades in a very short time. With changing communication landscape, media need faster response to timely combat negative impact on the program. It was realized that a critical factor in success of the program is parent's regular interaction with health professionals, which can address their concerns from evolving situations. ${ }^{10}$ It is worth mentioning that vaccine hesitance is present in developed countries too. Recent surge in measles cases leading to multiple outbreaks in Europe and Americas is more than often associated with communities or cults that fail to provide right of vaccination of their children. The post-crisis period is important, for revisiting the communication strategies to effectively address community concerns, answer parent's questions regarding well being of their children and more importantly create demand for vaccination. The recent rise in polio cases in Pakistan demands a thorough and systematic re-evaluation of the implementing strategies. It needs to look beyond the limitations, in order to appraise the threats and challenges. Previously, few local researchers identified the concerns of community about the vaccine safety, religious misinterpretations, perception and beliefs about the polio vaccine and geopolitical controversies about the vaccination program. ${ }^{11-13}$

While these new challenges would keep on posing threats to the eradication 
efforts, designing new strategies and revisiting crisis communication plans can help in addressing these challenges and threats. There is a need of contextualbased and comprehensive qualitative research, which can address the factors affecting the parents/community decisionmaking regarding polio vaccination. There is also a need to learn lessons from success stories in polio eradication and use them for guiding program implementation. Research findings can enable the policy makers to plan according to changing communication landscape. There is a need to rebuild the link between health worker and community at grass root level, wherever it is broken and initiate a dialogue with vaccine hesitant elements. Advocacy for polio vaccination through print, electronic and social media can help in developing and maintaining community trust on vaccines. The polio legacy will have long lasting effects on routine immunization program and can be an entry point for other public health interventions. Hesitancy to vaccinate at this stage could not only endanger global polio eradication but also would affect other vaccine preventable diseases eradication and elimination programs.

\section{REFERENCES}

I. World Health Organization. Ten threats to global health in 2019. [Cited on June 20, 2019]. Available from URL: https://www.who.int/ emergencies/ten-threats-to-globalhealth-in-2019

2. Stuart-Harris C. Prospects for the eradication of infectious diseases. Rev Infect Dis I 984 May-Jun;6(3):405-I I.
3. Shawn D, Gold R. Survey of parents' attitudes to the recommended Haemophilus influenzae type b vaccine program. CMAJ 1987;136: I038-40.

4. Salmon DA, Moulton LH, Omer SB, DeHart MP, Stokley S, Halsey NA. Factors associated with refusal of childhood vaccines among parents of school-aged children: A case-control study. Arch Pediatr Adolesc Med 2005;159: 470-6. DOI: 10.100I/ archpedi. I59.5.470

5. Baumgaertner B, Carlisle JE, Justwan F. The influence of political ideology and trust on willingness to vaccinate. PLoS One 20।8; I3(I): e019I728. Published 2018 Jan 25. DOI:I0.137|/ journal.pone.0191728

6. Salmon DA, Dudley MZ, Glanz JM, Omer SB. Vaccine hesitancy: Causes, consequences, and a call to action. Vaccine 2015 Nov 27;33 Suppl 4:D667I. DOI: I0.I0I6/j.vaccine. 2015.09.035

7. Eskola J, Duclos P, Schuster M, MacDonald NE; SAGE Working Group on Vaccine Hesitancy. How to deal with vaccine hesitancy? Vaccine 2015 Aug 14;33(34):4215-7. DOI: 10.1016/j.vaccine.2015.04.043.

8. Independent monitoring board of the global polio eradication initiative. Every last hiding place. Fifteenth report: December 2017. [Cited on: June 20, 2019]. Available from URL: http://polioeradication. org/wpcontent/uploads/2017/I2/ polioeradication-I5th-IMB-Report-20I7-
II.pdf

9. Bezhan F, Shah M. Anti-program propaganda in Khyber Pakhtunkhwa province of Pakistan. Radio Free Europe/Radio liberty. April 27, 2019. [Cited on: June 20, 2019]. Available from URL: https://www.rferl. org/a/mass-panic-propaganda-andmobs-how-an-anti-polio-drive-cameto-a-screeching-halt-in-pakistan/ 2990709l.html

10. Leask J, Kinnersley P, Jackson C, Cheater F, Bedford H, Rowles G. Communicating with parents about vaccination: a framework for health professionals. BMC Pediatr $2012 \mathrm{Sep}$ 2I; I2: I54. DOI: I0.II86/I47I-243I12-154.

II. Murakami H, Kobayashi M, Hachiya M, Khan ZS, Hassan SQ, Sakurada S. Refusal of oral polio vaccine in northwestern Pakistan: a qualitative and quantitative study. Vaccine 2014 Mar I 0;32(I 2):I382-7. DOI: 10.1016/j.vaccine.2014.01.018.

12. Khan TM, Sahibzada MU. Challenges to health workers and their opinions about parents' refusal of oral polio vaccination in the Khyber Pakhtoon Khawa (KPK) province, Pakistan. Vaccine 2016 Apr 19;34( I8):2074-81. DOI: I0.10I6/j.vaccine.2016.03.008.

13. Khan T, Qazi J. Hurdles to the global antipolio campaign in Pakistan: an outline of the current status and future prospects to achieve a polio free world. J Epidemiol Community Health 2013;67:696-702. DOI: 10.1 136/jech2012-202162
CONFLICT OF INTEREST

Authors declared no conflict of interest GRANT SUPPORT AND FINANCIAL DISCLOSURE NIL

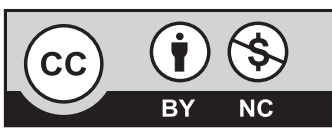

This is an Open Access article distributed under the terms of the Creative Commons Attribution-Non Commercial 2.0 Generic License.
KMUJ web address: www.kmuj.kmu.edu.pk

Email address: kmuj@kmu.edu.pk 